\title{
Tonal Changes in Hong Kong Cantonese
}

Lydia K.H. So

Department of Speech and Hearing Sciences, The University of Hong Kong, 5/F Prince Philip Dental Hospital, 34 Hospital Road, Hong Kong

This paper discusses changes in Hong Kong Cantonese tones. Cantonese is a tonal language and changes in its tones affect the semantics of the lexicon. There are nine tones in Cantonese, of which six are contrastive and there are three allotones of three level tones. Two variants of the High tone (High Level and High Fall) are found in the speech of Guangzhou speakers whereas the Hong Kong speakers only use the High Level form. In this paper, the High Rise and the Low Rise tone contours are found to be 25 and 23 respectively instead of 35 and 13 as thought previously. This change in Hong Kong Cantonese is contrasted with the Cantonese of Guangzhou and the paper posits that the differences are ascribable to the separation of Hong Kong and Guangzhou during much of the past 50 years.

\section{Introduction}

Over the past 50 years there have been significant tonal changes in Hong Kong Cantonese. These changes include tone choice and tonal contours. This paper discusses changes in Hong Kong Cantonese tones.

Cantonese is a tonal language with tone as an important component in the syllable. Change in tone affects the semantics of the lexicons. Tones are differentiated by their relative contours rather than their absolute values. While there are different tone descriptions, six contrastive tones with three entering tones which are allotones of the three level tones are recognised in Hong Kong Cantonese (e.g. Hashimoto,1972; Fok, 1974; Yuan, 1983;Cheung, 1986;Zee, 1991). The three level tones are known as the High Level tone, (HL), the Mid Level tone (ML) and the Low Level tone (LL). These three level tones differ from each other mainly in height. The High Rise tone (HR) and the Low Rise tone (LR) both have rising contours but rise to different levels. The falling tone is known as the Low Fall tone (LF) and has a falling contour. The three entering tones, High Entering tone $(\mathrm{H})$, Mid Entering tone $(\mathrm{M})$ and Low Entering tone (L) are treated as allotones of the HL, ML and LL tones respectively as they have similar heights and differ only in length.

Syllables with contrastive tones are characterised by open syllables or closed syllables ending with /m, n, $\hat{I}$ / e.g. / sam / 三 , / san/ 山 , / sấ / 生 , while the syllables with entering tones are closed with /p, t, k/e.g. / ap/ 鴨 , / at/ 壓， /ak/ 軛 . There is an exception to this generalisation as syllables with changed high rise tones may close with stops. These tones result from a colloquial tone change to syllables.

In the literature, different authors give different tonal values to Cantonese tones. Table 1 gives a summary of the tonal values that some authors have given to Cantonese tones. The first number in the tone value represents a tone's starting point, the second number represents its ending point. 
Table 1 The Cantonese tonal system according to different scholars

\begin{tabular}{|l|c|c|c|c|c|c||}
\hline Tones & Chao & Hashimoto & Vance & Zee & Bauer & Kei et al. \\
\hline HL & 55 & 53 & 55 & 55 & 55 & 55 \\
\hline HR & 35 & 35 & 35 & 24 & 25 & 25 \\
\hline ML & 33 & 44 & 33 & 33 & 33 & 33 \\
\hline LF & 21 & 21 & 11 & 21 & 21 & 21 \\
\hline LR & 23 & 24 & 13 & 23 & 23 & 23 \\
\hline LL & 22 & 33 & 22 & 22 & 22 & 22 \\
\hline H & 5 & 5 & & 5 & & \\
\hline M & 3 & 4 & & 3 & & \\
\hline L & 2 & 3 & & 2 & & \\
\hline
\end{tabular}

\section{One or Two Variants of the High Level Tone?}

Today, two variants of the high basic tone (High Level and High Falling tones) are found in Guangzhou Cantonese, whereas only the High Level tone is used in Hong Kong Cantonese. The High Falling tone is assimilated to the High Level tone if it is followed by a High Level tone (Chao, 1947). High Level tones are often associated with concrete nouns while the High Falling tones are found in abstract nouns, verbs, etc.

Bauer (forthcoming) reports that the two Guangzhou Cantonese-speakers whose speech he recorded and analysed have both High Level and High Falling tones. The High Level and the High Falling tones have been described for Hong Kong Cantonese (e.g. Chao, 1947; Lau, 1977). In fact, some Hong Kong Cantonese-speakers used both the High Level and the High Falling tones (cf. Fok, 1974). However, recent work on the tone contours of Hong Kong Cantonese reports that either the High Level tone is used by Hong Kong Cantonese speakers or that they do not distinguish between the High Level and the High Falling tones (Bauer (forthcoming), Kei, Symth, So, Lau \& Capell (forthcoming)). Child tone acquisition data also supports the finding that the High Level tone is preferred in Hong Kong Cantonese (Tse, 1976; Tse, 1991; So \& Dodd, 1995).

Loss of the High Falling tone in Hong Kong Cantonese is an interesting phenomenon. A difference between the Guangzhou and Hong Kong Cantonese tonal systems can be treated sociologically. There has been a definite separation between Guangzhou speakers and Hong Kong speakers for nearly 50 years, since the formation of the People's Republic of China. Hong Kong and Guangzhou have been under different sovereign powers for almost 100 years. These two communities experienced different social, linguistic and political influences. Such separation would allow the evolution of distinguishable forms.

\section{Are the Mid Level and the Low Rise Tones Merging?}

Killingley S.Y. (1979) stated that there were only five tones in Cantonese, namely, the High Level, the Mid Rising, the Mid Level, the Low Level and the Very Low Level tones. Killingley (1985) proposed a merger of the Mid Level and 
the Low Rise tones of Hong Kong Cantonese. However, her Cantonese tonal system was not accepted by mainstream Cantonese - only by Malaysian Cantonese. Similarly her proposal for merging the Hong Kong Mid Level and Low Rise tones is not supported by Hong Kong phonologists, though for some lexicons variations exist, e.g. $/ \mathrm{si}_{3 / 5}, \mathrm{syn}_{3 / 5} /$. From acoustic data, Kei et al. (forthcoming) and from acquisition data (Tse, 1978; Tse, 1991; So \& Dodd, 1995), there is no sign of any merger of the Mid Level and the Low Rise tones. To conclude, there are still six contrastive tones in Hong Kong Cantonese.

\section{What are the Tone Contours of the High Rise and the Low Rise Tones?}

Bauer (forthcoming) measured the tone contours of five speakers by the computerised spectrographic program WINCECIL ${ }^{1}$ and concluded that the High Rise tone starts as low as the Low Rise tone but reaches much higher than the Low Rise tone at its ending point. Hence, the tone numbers 25 describe the High Rise tone contour better than the traditional 35. From that study, Bauer also concluded that the Low Rise tone contour would be better represented by the tone numbers 23 than 13. Bauer's suggestion is well supported by Kei et al.'s findings. Kei et al studied 56 Hong Kong Cantonese-speakers aged between 19-22 and concluded that the tone contours for the High Rise tone are 25 and 23 respectively.

So \& Varley (1991) studied the lexical comprehension of 101 Hong Kong Cantonese-speakers and found that their subjects often confused the High Rise and the Low Rise tones. They explain this phenomenon as mainly due to the similar starting points of these two tones. Since the Low Rise Tone has a similar starting point to the High Rise tone, the Low Rise Tone contour would be better represented by tone levels 23 than 13 .

\section{Conclusion}

In conclusion, it can be stated that some aspects of the Hong Kong tonal system have changed and continue to change while other aspects remain stable. Social, linguistic and political factors seem to underlie these changes. In the first half of this century, the inhabitants of Hong Kong and Guangzhou would normally have travelled between the two cities. For many years during the latter half of this century Guangzhou has been separated from Hong Kong, which has developed and changed dramatically. Distinct sets of circumstances in the two cities have separated the influences affecting the Cantonese heard in each, and, accordingly, the characteristics of Hong Kong Cantonese and Guangzhou Cantonese are different. The determinants of particular changes remain to be specified. With the change of sovereignty in 1997, the social, linguistic and political factors may change radically within a short time. Whether the tonal system of Hong Kong Cantonese will become more like that of Guangzhou remains to be seen.

\section{Note}

1. Windows application for the Computerised Extraction of Components of Intonation in Language. 


\section{References}

Bauer R.S. (forthcoming) Hong Kong Cantonese tone contours. In S. Matthews (ed.) Studies in Cantonese Linguistics. Hong Kong: Linguistics Society of Hong Kong.

Chao, Y.R. (1947) Cantonese Primer. Cambridge: Harvard University Press.

Cheung, K.H. (1986) The phonology of present day Cantonese. Unpublished doctoral thesis, University of London.

Fok, C.Y.C. (1974) A Perceptual Study of Tones in Cantonese. Hong Kong: University of Hong Kong Press.

Hashimoto, A. (1972) Studies in the Yue Dialect. Cambridge: The University Press.

Kei, J., Smyth, V., So, L.K.H., Lau, C.C. and Capell, K. (forthcoming) Classification of Cantonese Lexical Tones: A Mathematical Approach.

Killingley, S.Y. (1979) Internal Structure of the Cantonese Word and General Problems of Word Analysis in Chinese. Kuala Lumpur: Penerbrit Universiti Malaya.

Killingley, S.Y. (1985) A New Look at Cantonese Tones: Five or Six? Newcastle Upon Tyne: Grevatt \& Grevatt.

Lau, S. (1977) A Practical Cantonese-English Dictionary. Hong Kong: The Government Printer.

So, L.K.H. and Varley, R. (1991) Cantonese Lexical Comprehension Test. Department of Speech and Hearing Sciences: University of Hong Kong.

So, L.K.H. and Dodd B. (1995) The Acquisition of Phonology by Cantonese-speaking Children. Journal of Child Language 22 (3), 473-95.

Tse, C.Y. (1991) The acquisition process of Cantonese phonology: A case study. Unpublished M. Phil. thesis, University of Hong Kong.

Tse, K.P. (1978) Tone acquisition in Cantonese: A longitudinal case study. Journal of Child Language 5, 191-204.

Vance, T.J. (1977) Tonal distinction in Cantonese. Phonetica 34: 93-107.

Yuan (1983) Essentials of Chinese Dialectology. Beijing: Wenzi Gaige Publisher.

Zee, E. (1991) Chinese (Hong Kong Cantonese). Journal of the International Phonetic Association 21 (1), 46-8. 